\title{
Effect of economic benefit for Paeonia ostii barks in difference cultivation management treatments
}

\author{
Rui $\mathrm{Xu}^{1 \dagger}$, Jun-Hui Zhao ${ }^{2,3 \dagger}$, Zhi-jun Wang ${ }^{1,2}$, Han Zhao ${ }^{3}$, Ying Luo ${ }^{3}$, Jin-Feng Liu ${ }^{3,4}$, Gao-pu ZHU ${ }^{3}$, Ji-Hong Han ${ }^{4 *}$, \\ and Chen Liang ${ }^{1,2 *}$ \\ ${ }^{1}$ Henan Forestry Vocational College, 471002, Luoyang, P. R. China \\ ${ }^{2}$ Luoyang Academy of Agriculture and Forestry Sciences, 471023, Luoyang, P. R. China \\ ${ }^{3}$ Non-timber Forest Research and Development Center, Chinese Academy of Forestry, 450003, Zhengzhou, P. R. China \\ ${ }^{4}$ Puyang City Appearance Environment Sanitation Management Department, 457001, Puyang, P. R. China
}

\begin{abstract}
To increase the yield and quality of Paeonia ostii barks, the research of economic income under Juglans regia trees in difference cultivation management treatments were explored. Four treatments were designed in this study, removing flower bud (T1), clip deadwood and root tillers (T2), spraying Bordeaux mixture on the leaves (T3) and commonly management (T4, CK). The results showed that the yield of cortex moutan in total, first grade and second grade were significantly higher $(p \leq 0.05)$ than $\mathrm{CK}$, among these treatments, $\mathrm{T} 3$ reached to $102.1 \mathrm{~g}$ per tree that was the highest grades. In quality part, T1 and T2 were not significant than treatment $\mathrm{CK}$ in paeonol contents, but the T3 was the significantly higher $(p \leq 0.05)$ than $\mathrm{CK}$ and reached to $1.82 \%$ contents. In economic input, treatments were obvious higher than $\mathrm{CK}$, and the T3 reached to $67780.5 \mathrm{RMB}$ that was $13935.5 \mathrm{RMB}$ higher than $\mathrm{CK}$. The leaves disease might be main negative factor for yield and quality of cortex moutan in Luoyang area, Henan province, so spraying Bordeaux mixture with concentration bluestone: quicklime: water = 1: 2: $200(\mathrm{w} / \mathrm{w})$ on the leaves from middle May to harvest of Paeonia ostii interval $20 \mathrm{~d}$ at every year was the best methods in this study because it had small difficulty management, lower labour intensity and higher benefit results in suitable for application in the cultivation model of intercropping Paeonia suffruticosa under Juglans regia trees.
\end{abstract}

\section{Introduction}

Paeonia ostii T. Hong et J.X. Zhan barks (Cortex moutan) is a raw material of traditional Chinese herbal medicine. It is rich in paeoniflorin and paeonol, which has many medicinal effects such as heat-clearing, promoting blood circulation, relieving pain, anti-inflammatory, antipyretic and inhibiting allergic reaction [1]. P. ostii has a large demand in the Chinese market and has a high economic value. For a long time, due to excessive pursuit of production and neglect of quality, the total production of cortex moutons is high, but the supply of high-quality medicinal materials is insufficient. The study found that the quality of cortex moutons, in addition to variety differences, is mainly affected by tree age and cultivation techniques [1-2]. For $P$. ostii, it usually takes more than 4 years to reach the medicinal standard [1]. Cutting old shoots significantly increase the yield of cortex moutons [2]; in terms of cultivation patterns, oil peony and Populus spp., Toona sinensis were developed. Intercropping practice of Zanthoxylum bungeanum, Amygdalus persica, Malus pumila, Pyrus spp., Camellia oleifera, etc., and achieved good results [3]. Juglans regia is a tall deciduous tree, and the common cultivated row spacing in domestic production is $4 \mathrm{~m} \sim 6 \mathrm{~m}$. By 2016, the cultivated area of walnut in China was more than 5.3 million $\mathrm{hm}^{2}$ [4], and a large area of understory land was urgently needed to be developed and utilized to improve comprehensive benefits. In recent years, the experiment of planting peony under the walnut forest found that the shading environment under the walnut forest reduced the light inhibition of peony and promoted the growth and development [5], which increased the yield of $P$. ostii barks [6]. The harvested peony seeds have high oil production rate and excellent quality [3,7], and the land use efficiency and economic benefits are significantly improved. In order to improve the yield and quality of local $P$. ostii, the $P$. ostii originating from southern Anhui was introduced to Luoyang, Henan Province, belongs to the Huang-Huai River Basin. It was found that planting P. ostii under walnut forest promoted the formation and quality of walnut, but it was not good for the flowering of P. ostii peony. [6] In order to explore the causes of this phenomenon and maximize the benefits, based on previous research, after the introduction of $P$. ostii peony from Anhui to Luoyang, different cultivation and management measures such as flower bud, pruning and sprayed Bordeaux mixture were adopted to achieve the

*Corresponding author: poog502@hotmail.com (Ji-Hong Han); lcjjlgg@sina.com (Chen Liang) 
purpose of improving the content and yield of active ingredients in $P$. ostii paeonol. The effect of increasing production and increasing income was significant.

\section{Materials and methods}

\subsection{Experimental area}

Experimental area was located in Tianfeng walnut cultivation professional cooperatives, Luoyang city, Henan province (N $34^{\circ} 20$ '27', '112 ${ }^{\circ} 33^{\prime} 43$ 'E'), the covers an area of $7.5 \mathrm{hm}^{2}$. Climate type is a warm temperate continental monsoon climate, sufficient sunlight, mild climate, four seasons, the annual average sunshine hours $2177.3 \mathrm{~h}$, sunshine percentage of $49 \%$, annual average temperature of $14{ }^{\circ} \mathrm{C}$, annual average rainfall of $690 \mathrm{~mm}$, annual frost-free period $213 \mathrm{~d}$. It is a typical dry land with shallow hills and hills, and the soil is red clay. The content of organic matter is $11.1 \mathrm{~g} \cdot \mathrm{kg}^{-1}$, available nitrogen is $62.3 \mathrm{mg} \cdot \mathrm{kg}^{-1}$, available phosphorus is $13.1 \mathrm{mg} \cdot \mathrm{kg}^{-1}$, and available potassium is $151.1 \mathrm{mg} \cdot \mathrm{kg}^{-1}$. In early March 2010, the grafted seedlings of walnut varieties planted. The varieties were mainly composed of 'Zhongsong No.1' and 'Xiangling', 'Liaoning No.1' were pollinated varieties. The trunk height was $1.2 \mathrm{~m}$, and the planting density was $3 \mathrm{~m} \times 5 \mathrm{~m}$, about 667 plants $\cdot \mathrm{hm}^{-2}$, the tree shape is trimmed into a small crown and sparse layer shape. The first year's canopy density is about $10 \%$. In the second year, there is fruit, and the canopy density is about $25 \%$. In the third year of the fruiting period, the canopy density is about $35 \%$. In the fourth year of fruiting period, the canopy density is about $55 \%$. In the fifth year, it enters the high yield period, and the canopy density is about $80 \%$.

In late October 2010, the family seedlings of the second-year-old medicinal $P$. ostii were planted. The planting method was as follows: the planting distance was $1.0 \mathrm{~m}$ away from the walnut plant, the density was $0.4 \mathrm{~m} \times$ $0.5 \mathrm{~m}$, and the $1.0 \mathrm{~m}$ road was left in the middle. 22,500 plants per $\mathrm{hm}^{-2}$. The harvest of cortex moutan: the content of paeonol in $P$. ostii barks is greatly affected by the age of peony trees, and the older, the higher the content of salvianol [8]. The harvesting period had a great influence on the content of paeonol. According to Bai et al. [8], the 5-year-old root barks of $P$. ostii was harvested in early October 2015, and the yield and quality were determined by random sampling. Conventional field management.

\subsection{Planting management and field experiment design}

Experiment design was divided into four treatments: T1 pick the flower bud, on the basis of conventional field management, budding period in March every year to excise P. ostii bud; T2 - cut twigs and root shoot, on the basis of conventional field management, prior to the annual bud cut twigs, timely cut off in $4 \sim 5 P$. ostii base new tillers; T3 - spray the Bordeaux preventive solution on the leaf surface of $P$. ostii. On the basis of conventional field management, spray the protective agent Bordeaux mixture on the surface of $P$. ostii every 20 days from mid-
May every year, and spray the time until $P$. ostii The leaves are withered (the leaves lose their function in late October), and it is appropriate to spray 5 to 6 times a year. If there is rain during the spraying, it will be sprayed again after the rain. Bordeaux liquid formula according to copper sulfate: quicklime: water $=1: 2: 200(\mathrm{w} / \mathrm{w})$ ratio; $\mathrm{T} 4$ - control, conventional field management of intercropping $P$. ostii peony, weeding when weed height exceeds $P$. ostii when $P$. ostii Watering when the leaves are withered. The random block design is divided into 3 sub-cells with an area of $60 \mathrm{~m} 2$ per plot. It is treated in the second year (2011) of $P$. ostii peony planting, and P. ostii barks harvested for 4 consecutive years until early October 2015.

\subsection{Detection method}

Twenty plants of $P$. ostii were randomly selected from each plot to investigate the yield, quality grades and paeonol contents of $P$. ostii barks. P. ostii barks was produced by dry weighing method, and the quality classification was based on Zhang et al. [1] (Table 1); paeonol content was determined by reference to Yang [9] and other methods using High Performance Liquid Chromatography (HPLC) with a little improvement. Specifically, the barks were graded according to the standard, placed in a kraft envelope, and dried in a blast oven at $40^{\circ} \mathrm{C}$ to a constant weight, and $10 \mathrm{~g}$ of dried was placed in a pulverizer. Weighing balance (PL203, Mettler, Germany) weigh $0.50 \mathrm{~g}$ into a conical flask, added $50.0 \mathrm{ml}$ of methanol, seted the ultrasonic (HT-300BQ, Jining Hengtong, China) power to $300 \mathrm{~W}$, frequency $50 \mathrm{Khz}$ sonication for $30 \mathrm{~min}$. The mixture was filtered through a microporous membrane $(0.20 \mu \mathrm{m})$, and the filtrate was weighed by a pipette (Research plus $1000 \mu \mathrm{L}$, Gillson, Germany) to $1.0 \mathrm{ml}$, and methanol was added to $10 \mathrm{ml}$ to prepare a sample. Take reference product (purchased from China Food and Drug Administration Institute), added methanol to make $20 \mu \mathrm{g}$. Control sample were respectively taken up, and injected into a HPLC (Waters 1525, Waters, USA) to determine the content of paeonol. All drugs were of chromatographic purity.

The formula for calculating the content of Paeonol was: Paeonol content $(\%)=\frac{A_{0} / A_{1} \times C_{1} \times N}{M} \times 100 \%$

In the above formula, $\mathrm{A}_{0}$ - the peak area of the sample, $\mathrm{A}_{1}$ - the peak area of the control, $\mathrm{C}_{1}$ pair - the concentration of the control, the $\mathrm{N}$ - sample dilution factor, and the $\mathrm{M}$ sample weight.

Table 1. The grade standard of Paeonia ostii barkswhich reducing

\begin{tabular}{llll}
\hline Grades & $\begin{array}{l}\text { Length } \\
/ \mathrm{cm}\end{array}$ & $\begin{array}{l}\text { Middle circumference } \\
\text { coarse } / \mathrm{cm}\end{array}$ & $\begin{array}{l}\text { Paeonol } \\
\text { content/ } \%\end{array}$ \\
\hline G1 & $>6$ & $>2.5$ & $1.237 \pm 0.081$ \\
G2 & $>5$ & $>1.8$ & $1.168 \pm 0.502$ \\
G3 & $>4$ & $>1.0$ & $1.040 \pm 0.298$ \\
G4 & $\leq 4$ & $\geq 0.6$ & $0.981 \pm 0.227$ \\
G5 & $\leq 4$ & $\geq 0.6$ & $0.981 \pm 0.227$ \\
\hline
\end{tabular}




\subsection{Data Analysis}

Benefit analysis: the price of cortex moutan in different grades was based on the price of the local medicinal market. The first grade was $36 \mathrm{RMB} \cdot \mathrm{kg}^{-1}$, the second grade was $32 \mathrm{RMB}^{\cdot} \mathrm{kg}^{-1}$, the third grade was $27 \mathrm{RMB}^{\circ} \mathrm{kg}^{-}$ ${ }^{1}$, grade 4 and others was $21 \mathrm{RMB}^{\cdot} \mathrm{kg}^{-1}$; local temporary daily wage was $50 \mathrm{RMB} \cdot 8 \mathrm{~h}^{-1}$, picking flower buds, pruning work efficiency needed 15 people $\cdot \mathrm{hm}^{-2} \cdot \mathrm{d}^{-1}$. The labor in the growing season was about 90 120 workers $\cdot \mathrm{hm}^{-2}$, which was $6000 \mathrm{RMB} \cdot \mathrm{hm}^{-2}$; the Bordeaux liquid powder was calculated at $15 \mathrm{RMB} \cdot 500 \mathrm{~g}^{-1}$, the dosage was about $15.0 \mathrm{~kg} \cdot \mathrm{hm}^{-2}$, and the spray medicinal worker was about $1500 \mathrm{RMB} \cdot \mathrm{hm}^{-2} \cdot \mathrm{d}^{-1}$, accumulated 600 $\mathrm{RMB} \cdot \mathrm{hm}^{-2}$, continuous spraying 5 6 times, totaling 3600 $\mathrm{RMB} \cdot \mathrm{hm}^{-2}$; cortex moutan harvesting and grading once invested about $1500 \mathrm{RMB} \cdot \mathrm{hm}^{-2}$. The other cost (including peony seedlings, organic fertilizers, fertilizers, hydropower, etc.) was about 12,000 15,000 RMB $\cdot \mathrm{hm}^{-2}$. The proceeds were estimated based on the average of the cortex moutan price and the highest value of the inputs.

Data entry, preliminary processing and statistical analysis were performed using Office Excel 2010. Data significance variance analysis and Ducan multiple comparison were performed using DPS v6.50 [10], and the significance was set to 0.05 level.

\section{Results and analysis}

\subsection{Effect of different treatments on the yield of Paeonia ostii barks}

Table 2. Effect of quality of Paeonia ostii barks in different treatments

\begin{tabular}{lllllll}
\hline \multirow{2}{*}{$\begin{array}{c}\text { Treat- } \\
\text { ments }\end{array}$} & $\begin{array}{c}\text { Yield } \\
/ \mathrm{g}\end{array}$ & \multicolumn{6}{l}{ Grades of cortex moutan } \\
\cline { 3 - 7 } & $\mathrm{G} 1$ & $\mathrm{G} 2$ & $\mathrm{G} 3$ & $\mathrm{G} 4$ & $\mathrm{G} 5$ \\
\hline \multirow{2}{*}{$\mathrm{I}$} & $98.5 \pm$ & $38.7 \pm$ & $32.4 \pm$ & $12.3 \pm$ & $10.9 \pm$ & $4.2 \pm$ \\
& $2.3 \mathrm{bc}$ & $1.2 \mathrm{a}$ & $2.2 \mathrm{a}$ & $0.8 \mathrm{a}$ & $0.3 \mathrm{a}$ & $0.1 \mathrm{ab}$ \\
II & $94.7 \pm$ & $39.4 \pm$ & $30.1 \pm$ & $14.7 \pm$ & $8.2 \pm$ & $2.3 \pm$ \\
& $1.9 \mathrm{c}$ & $1.9 \mathrm{a}$ & $1.6 \mathrm{a}$ & $0.5 \mathrm{a}$ & $0.2 \mathrm{a}$ & $0.3 \mathrm{a}$ \\
III & $102.1 \pm$ & $37.7 \pm$ & $35.4 \pm$ & $10.6 \pm$ & $11.8 \pm$ & $6.6 \pm$ \\
& $3.0 \mathrm{ab}$ & $0.9 \mathrm{a}$ & $1.8 \mathrm{a}$ & $0.4 \mathrm{a}$ & $0.8 \mathrm{a}$ & $0.7 \mathrm{~b}$ \\
IV & $81.3 \pm$ & $29.3 \pm$ & $28.1 \pm$ & $9.2 \pm$ & $8.7 \pm$ & $6.0 \pm$ \\
(CK) & $1.6 \mathrm{~d}$ & $1.1 \mathrm{~b}$ & $1.3 \mathrm{~b}$ & $0.7 \mathrm{a}$ & $0.1 \mathrm{a}$ & 0.2
\end{tabular}

Note: $P$. ostii barks is obtained by planting, which is 2 years old, for 5 years. The different letters in the same column indicate significant difference, $p \leq 0.05$, and the fellow are the same.

In terms of yield, the treatments $\mathrm{T} 1, \mathrm{~T} 2$ and $\mathrm{T} 3$ were significantly $(p \leq 0.05)$ higher than control group (T4) (Table) 2) The above treatments increased by $21.2 \%$, $16.5 \%$, and $25.6 \%$, respectively, indicating that the treatment measures were significant $(p \leq 0.05)$, which promoted the increase of paeon yield. Among them, the treatment of T3 obtained the highest yield of paeonol, followed by $\mathrm{T} 1$, and theT2 (Table 2 ).

In terms of yield control of different grades, the yields and the secondary were significantly higher $(p \leq 0.05)$ than the control (Table 2), indicating that the treatment significantly promoted paeonia content formation. The quality of the cortex moutan was improved, but the yields were not significantly different among treatments $(p \leq$
0.05) except T4, indicating that the different treatments did not differ significantly in improving the yields. For the third- and fourth-grade $P$. ostii barks, the difference among the treatment group and the control was not significant (Table 2), indicating that the third- and fourth-stage yields of cortex moutan were relatively stable, and were less affected by farming operations. The yield of grade 4 was low, which reduced the overall yield and quality.

\subsection{Effect of paeonol contcan increase the yield and quality of cortex moutan, paeonol content up to $1.51 \% \sim 2.31 \%$, the average value of $1.88 \%$ ent of Paeonia ostii barks in different treatments}

Table 3. Effect of paeonol content of Paeonia ostii barks in different treatments

\begin{tabular}{llllll}
\hline \multirow{2}{*}{ Treatment } & \multicolumn{6}{l}{ Grades of cortex moutan $/ \%$} \\
\cline { 2 - 6 } & G1 & G2 & G3 & G4 & G5 \\
\hline \multirow{2}{*}{ I } & $1.53 \pm$ & $1.61 \pm$ & $1.81 \pm$ & $2.03 \pm$ & $2.27 \pm$ \\
& $0.0 \mathrm{a}$ & $0.1 \mathrm{a}$ & $0.2 \mathrm{a}$ & $0.3 \mathrm{a}$ & $0.5 \mathrm{a}$ \\
II & $1.51 \pm$ & $1.65 \pm$ & $1.78 \pm$ & $1.97 \pm$ & $2.21 \pm$ \\
& $0.1 \mathrm{a}$ & $0.1 \mathrm{a}$ & $0.2 \mathrm{a}$ & $0.2 \mathrm{a}$ & $0.0 \mathrm{a}$ \\
III & $1.68 \pm$ & $1.82 \pm$ & $1.87 \pm$ & $2.21 \pm$ & $2.31 \pm$ \\
& $0.1 \mathrm{~b}$ & $0.3 \mathrm{~b}$ & $0.3 \mathrm{a}$ & $0.1 \mathrm{~b}$ & $0.2 \mathrm{a}$ \\
IV(CK) & $1.54 \pm$ & $1.59 \pm$ & $1.86 \pm$ & $2.17 \pm$ & $2.27 \pm$ \\
& $0.2 \mathrm{a}$ & $0.0 \mathrm{a}$ & $0.3 \mathrm{a}$ & $0.3 \mathrm{ab}$ & $0.1 \mathrm{a}$ \\
\hline
\end{tabular}

In terms of improving the quality of cortex moutan, T3 significant increase paeonol content of crude medicine in the G1 and G2 (Table 3), one of which was P. ostii barks has a maximum paeonol content of $1.68 \%$ and a grade 2 paeonol content of $1.82 \%$. The difference between the other treatments was not significant, indicating that T3 was a significant effect on improving the content of paeonol in $P$. ostii barks; There was no significant difference in the content of paeonol in the G3, G4 and G5, indicating that the paeonol content in the G3 and below grades was relatively stable and was less affected by external factors. The content of paeonol in Grade 4 in T3 and T4 was significantly higher than that in T1 and T2, indicating that $\mathrm{T} 1$ and $\mathrm{T} 2$ inhibited the content of paeonol in grade 4, and T3 maintained stabilization of paeonol content in grade 4 .

\subsection{Comparative analysis of economic profit under different treatments}

Table 4. Analysis of ecnomic income of Paeonia ostii barks

\begin{tabular}{|c|c|c|c|c|c|}
\hline & & I & II & III & IV(CK) \\
\hline \multirow{3}{*}{$\begin{array}{l}\text { Income } \\
\text { of } \\
\text { cortex } \\
\text { moutan }\end{array}$} & G1 & 31347.0 & 31914.0 & 30537.0 & 23733.0 \\
\hline & G2 & 27864.0 & 28366.5 & 27144.0 & 21094.5 \\
\hline & G3 & 19683.0 & 18286.5 & 21505.5 & 17071.5 \\
\hline \multirow{2}{*}{$\begin{array}{l}/ \mathrm{RMB} \cdot \\
\mathrm{hm}^{-2}\end{array}$} & G4 \& G5 & 7135.5 & 4962.0 & 8694.0 & 6946.5 \\
\hline & In total & 86029.5 & 83529.0 & 87880.5 & 68845.5 \\
\hline \multirow{5}{*}{$\begin{array}{l}\text { Cost of } \\
\text { cortex } \\
\text { moutan } \\
/ \mathrm{RMB} \text {. } \\
\mathrm{hm}^{-2}\end{array}$} & $\begin{array}{l}\text { Take off } \\
\text { the flower } \\
\text { bud }\end{array}$ & 6000.0 & - & - & - \\
\hline & $\begin{array}{l}\text { Pruning } \\
\text { branches }\end{array}$ & - & 6000.0 & - & - \\
\hline & Spraying & - & - & 3600.0 & - \\
\hline & $\begin{array}{l}\text { Production } \\
\text { materials }\end{array}$ & 15000.0 & 15000.0 & 15000.0 & 13500.0 \\
\hline & Mechanical & 1500.0 & 1500.0 & 1500.0 & 1500.0 \\
\hline
\end{tabular}




\begin{tabular}{ccccc}
\hline In total & 22500.0 & 22500.0 & 20100.0 & 15000.0 \\
\hline $\begin{array}{l}\text { Average profit / RMB } \\
\mathrm{hm}^{-2}\end{array}$ & 63529.5 & 61029.0 & 67780.5 & 53845.5 \\
\hline
\end{tabular}

At present, the acquisition of $P$. ostii barks in Luoyang was based on different grades. The $P$. ostii barks with highquality are of higher price, the poor-quality are lower, and the G4 and G5 are acquired at the uniform price according to the currency standard. From the market situation of $P$. ostii barks, the income of T3 was the best, the income per $\mathrm{hm}^{2}$ was about $87880.5 \mathrm{RMB}$, followed by the T1, which was $86029.5 \mathrm{RMB}$, and the lowest income of $\mathrm{T} 2$ was 83529.0 RMB, which was 1.28 times of the comparison of 68845.5 RMB. From the aspect of input, the T3 was the lowest investment, which was $20100.0 \mathrm{RMB} \cdot \mathrm{hm}^{-2}$, and the total amount of labor and production materials of $\mathrm{T} 1$ and T2 were roughly equal, with an average of 22500.0 $\mathrm{RMB} \cdot \mathrm{hm}^{-2}$. From the aspect of income, the benefit of T3 was the best, reaching $6,7780.5 \mathrm{RMB} \cdot \mathrm{hm}^{-2}$, which was more $1,3935.0 \mathrm{RMB} \cdot \mathrm{hm}^{-2}$ than control (T4), followed by $\mathrm{T} 1$, which was $6,3529.5 \mathrm{RMB}$, and the lowest income of T2 was 6,1029.0 RMB $\cdot \mathrm{hm}^{-2}$. They were 1.26 times, 1.18 times and 1.13 times of the control group's income of 53845.5 $\mathrm{RMB} \cdot \mathrm{hm}^{-2}$, respectively.

\section{Discussion}

Paeonol is the main active ingredient of cortex moutan, which is greatly affected by the place of production. The content of paeonol in different places is significantly different. Luoyang, Henan is one of the main growing areas of peony in China. The annual income from the peony festival and the cortex moutan transaction has significantly increased the economic income of growers and has played an important role in regional precision poverty alleviation for a long time. However, the local cortex moutan in Luoyang mainly come from local peony varieties such as 'Luoyanghong' and other overage plants, which not only have low yield of paeonol, but also the quality is different due to different varieties. Qu et al [11] found that the paeonol content in P. ostii barks in China was as high as $3.53 \%$ in Tongling city, Anhui province, and the paeonol content in Luoyang city, Henan province was about $2.12 \%$. In this paper, we attempted to plant Paeonia ostii, which is native to Anhui, into Luoyang by means of introduction to further improve the quality, yield and benefits.

Normally, as the growth of the peony plant age, flowering amount increased year by year. Reproductive growth predominates, and the nutrients consumed by flowering hinder the formation and quality of $P$. ostii barks, and the removal of flower buds not only saves a lot of nutrients, but also breaks the internal hormone balance of plants. Extend the trophic growth period, adjust the "source-storage-flow" relationship, promote the formation of photosynthetic products and transport to the underground part, reduce the loss of above-ground nutrients, strengthen the accumulation of biomass in the underground part, and increase the yield of the rind. Similarly, the elimination of the withered branches and the germination of the roots reduces the competition and consumption of nutrients, increases the ventilation and light transmission between the plants, and enhances the plant growth potential. However, from the results of the experiment, the removal of flower buds, pruning of dead branches and new germination of tillers can improve the yield of paeonol, but the effect on increasing the content of paeonol was not significant, and the increase of artificial input indicates that it was not suitable. This result was different with Fang et al. [2]. They reported that the cutting of old branches significantly improved the yield of Paeonia ostii barks. The removal of flower buds, pruning of withered branches and new germination of tillers in this experiment had a significant effect on improving the yield of the peony, which may be related to the planting pattern. Compared with the Paeonia ostii barks pure forest researched by Fang et al. and others [2], the shading of the walnut tree inhibited the convection and enough illumination of the undersurface air in this study, which alleviated the occurrence of peony light inhibition events. At the same time, the barrier or competition of water, fertilizer, oxygen and heat by walnuts formed a stress on the peony, or the intercropping crop improved the soil mineral nutrition [12-13], thus increasing the yield of $P$. ostii barks.

Previous studies have found that $P$. ostii has a heavier disease in the leaf parts after planting in Luoyang, and the leaf spray protective agent Bordeaux mixture can effectively reduce the occurrence of leaf diseases and play a role of controlling diseases and supplementing trace elements. This ensured the enough photosynthesis of leaves. This study found that $P$. ostii, which sprayed Bordeaux mixture, was delayed by more than 40 days compared to the control defoliation time. It effectively prolongs the photosynthesis time, ensures the abundant nutrient supply of roots, and increases the effective ingredients, making the paeonol content up to $1.88 \%$, much higher than Zhang et al. [1] grading standard and Qu et al [11] to detect the level of $2.12 \%$ in Henan. Therefore, in Luoyang area, the inhibition of $P$. ostii leaf disease have been relatively more effective than the removal of flower buds, pruning dead branches and root germination (cutting old branches) [2] measures were more effective ways to increase the yield of $P$. ostii barks. At the same time, compared with the agricultural operations such as removing flower buds and pruning branches, the spraying of Bordeaux liquid had lower labor intensity and high operability, and can adapt to the future mechanized demand. In addition, the medicinal peony fruit is also rich in oil and protein content, and has good physical, chemical and functional properties. It is a new food ingredient in the food industry [14]. It was ideal for intercropping of "walnut + medicinal peony" management model.

\section{Conclusion}

In Luoyang, Henan Province, planting medicinal $P$. ostii under walnut tree can begin in the second year after walnut planting. At the beginning of mid-May, interval 20 days, the ingredient of Bordeaux mixture with copper sulfate: quicklime: water was 1: 2: $200(\mathrm{w} / \mathrm{w})$, until $P$. ostii barks harvest, This treatment can increase the yield and quality of cortex moutan, paeonol content up to $1.51 \% \sim 2.31 \%$, 
the average value of $1.88 \%$. This cultivation management model was worthy of application in local production.

\section{Acknowledgments}

This study was funded by the Fundamental Research Funds for the Central Non-profit Research Institution of CAF (Project number: CAFYBB2017ZA004-2) and National Forest Genetic Resource Platform (Project number: 2005DKA21003).

\section{References}

1. Y.F. Zhang, J. Wang, C.W. Fang, J. Li, J.H. Wu, J. Anhui Tradit. Chinese Med. Coll. 34, 10 (2015)

2. C.W. Fang, C. Yang, X.L. Liu, S.L. Wang, Z.Q. Wang, D.Q. Wang, J. Chinese Med. Mater. 32, 12 (2009)

3. S.Q. Xu, Q. Liu, S.W. Huang, S. Ni, G.R. Hu, Morden Hortic. 14, 2 (2017)

4. J.L. Deng, China Forest Pro. Ind. 6, 2 (2016)

5. Z. Tang, Z. Shen, X. Ding, J. Chen, Econ. Forest Res. 22, 3 (2017).

6. H. Yin, S. Wei, C. Liang, Z. Wang, X. Zhang, North. Hortic.14, 6 (2017).

7. H.B. Hwang, J.C. Kim, S.D. Park, F.S. Cui, Z.L. Lin, Korean J. Soil. Fert., 34, (1996)

8. Z.C. Bai, Sci. Agri. Sin. 39, 5 (2006)

9. Y. Yang, F. Peng, Z.C. Mo, W.H. Tai, W.Z. Luo, X. Liu, J. Chinese Med. Mater. 36, 3 (2013)

10. Q.Y. Tang, C.X. Zhang, Insect Sci. 20, (2013)

11. Y.P. Qv, J. Wang, H.Q. Gao, F. Li, L.L. Li, Z. Li, G.Z. Jiang, Z.J. Li, Chinese J. Pharm. 12, 11 (2015): 656659.

12. C.Q. Yu, H.Q. Lin, Y.H. Hou, Z.F. Shi, D.S. Lin, Adv. Mater. Res. 581, 1 (2012)

13. W. Cong, E. Hoffland, L. Li, J. Six, J.H. Sun, X.G. Bao, F.S. Zhang, W. Van Der Wer, Glob. Change Biol. 21, 4 (2015)

14. L.L. Gao, Y.Q. Li, Z.S. Wang, G.J. Sun, X.M. Qi, H.Z. Mo, Food Chem. 240, (2017) 